\title{
The truth lies between the lines
}

\section{Body \& Soul: Narratives of Healing from Ars Medica}

Allison Crawford, Rex Kay, Allan Peterkin, Robin Roger and Ronald Ruskin, editors, with Aaron Orkin

University of Toronto Press; 2011

I n the poem "Paterson," William Carlos Williams voices a neighbour's reaction when he reveals that he is a poet, as well as a physician: "It must be a great / thing to have such a pastime. / But you were always a strange / boy. How's your mother?" To many people, the combination of medicine and poetry does seem strange, because people tend to believe that science and technology have replaced the art in medicine. After all, if the body is a machine, and the doctor a technician whose job is to fix malfunctioning parts, where does art come in? What role can poetry possibly play?

Yet something is missing. As traditional components of the healer's art, like empathy and trust, ritual and narrative, drift farther and farther away from technological practice, all is not well. Patient satisfaction declines, anxiety increases, symptoms multiply and medical costs skyrocket. Physicians feel unfulfilled and experience burnout. Patients feel alienated from, but also addicted to, the treadmill of tests and treatments. No wonder Allan Peterkin and Robin Roger in their introduction to Body \& Soul pose the question, "What can patients and health practitioners do to address the growing divide between science and humanism?"

This is a crucial issue in medicine today. In North America, educators and practitioners have begun to address it by developing medical curricula in selfawareness, mindfulness, reflective practice and, especially, narrative medicine. Peterkin and Roger point to the ancient art of storytelling as the key to rehumanizing health care. Several years ago, with this premise in mind, these editors created Ars Medica, a literary magazine dedicated to "adding a narrative dimension to portrayals of the universal expe- rience of illness, treatment, and healing." Body \& Soul is an anthology of poetry, prose and visual art drawn from its first five years of publication.

The collection is divided into three sections, featuring narratives of patients, family and friends, and health care practitioners. It also includes a useful index that allows readers to select stories and poems by topic, like children and parenting, or chronic illness and aging. Remarkably, for an anthology based on a fairly small body of work, Body \& Soul contains excellent, highly illustrative, pieces in each section and for every topic. Perhaps "I, Michael" is the story that best illuminates the complex interaction of real and imagined worlds in a patient's confrontation with illness. It carries the reader into the mind of a young man suffering from amyotrophic lateral sclerosis (ALS), where he identifies with Michelangelo, who could visualize a fully formed statue inside a block of marble even before he began to liberate it with his mallet and chisel. This metaphor sustains Michael, as ALS reverses the process, gradually turning his body into stone. At the same time, Michael falls in love with Sheila, his nurse, and creates an alternate world in which someday they visit the Sistine Chapel as man and wife.

"The Cure of Metaphor" is another piece that gives expression to the power of metaphor in patient narratives. A patient awakes to discover that his vision has become blurry. An ophthalmologist tells him that the cause is "venous occlusion," a blockage of the retinal veins. But the patient, "not being from the scientific side of things," imagines "venous" to be Venus, goddess of love, and concludes that his "images were fading / Because they'd not been loved enough." A clinician narrative, "The Texture of a Word," demonstrates the explosive potential of a single word. A neurosurgical resident tells a patient his diagnosis, glioblastoma, a death sentence. The patient responds with devastating silence. Eventually, he murmurs, "Thank you, doctor ... for everything."

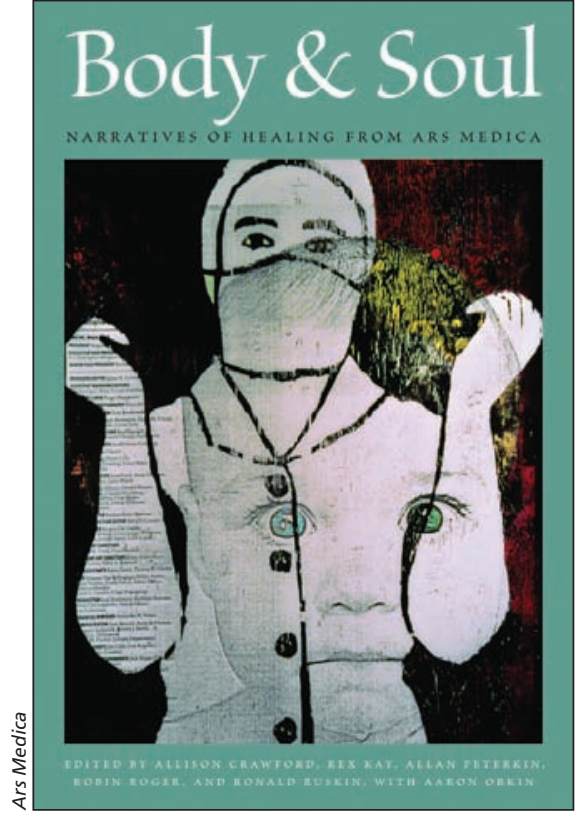

This powerful moment is reminiscent of the final line of Raymond Carver's poem, "What the Doctor Said," in which, after being told of multiple metastatic lesions in his lung, the poet writes, "I may even have thanked him habit being so strong."

"Accident Room," a thoroughly engaging story by Jay Baruch, weaves many strands of narrative into a seemingly routine emergency department encounter. Brick may, or may not, have fallen from his chair and later "mentioned" back pain. Brick, his wife, Old Doc Owens, young Doctor Diggs each one tells a different story, but, ultimately, the truth lies in listening between their lines. Similarly, for the attentive reader, Body \& Soul captures the complexity and impact of the illness experience, as illuminated through multiple narratives and images.

\section{Jack Coulehan}

Senior Fellow

Center for Medical Humanities,

Compassionate Care, and Bioethics

Stony Brook University

Stony Brook, NY

\section{References}

1. Williams WC. Paterson. New York (NY): New Directions; 1958. p. 114.

2. Carver R. What the doctor said. In: A new path to the waterfall. New York (NY): Atlantic Monthly Press; 1989. p. 113.

CMAJ 2013. DOI:10.1503/cmaj.120382 